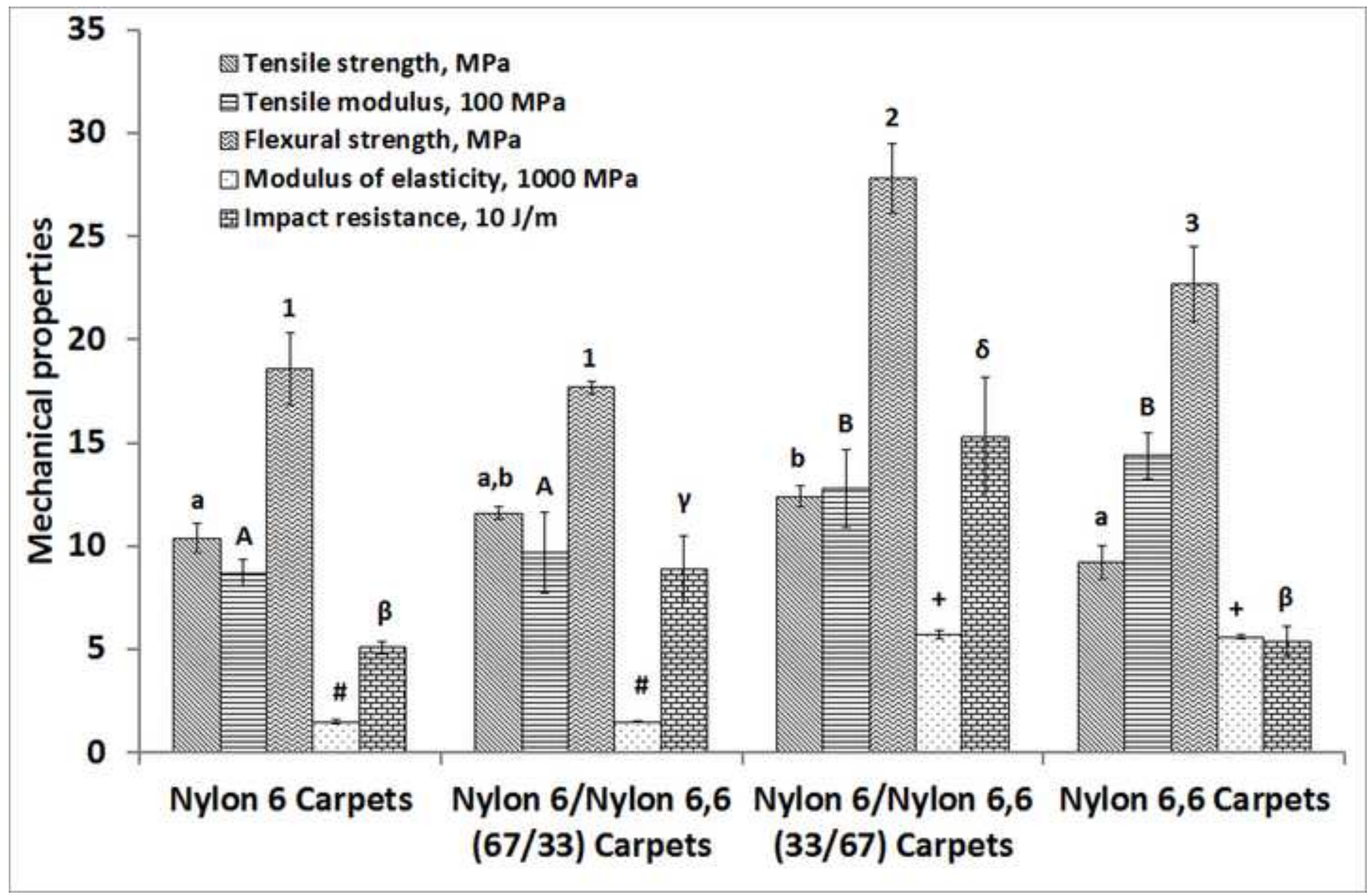




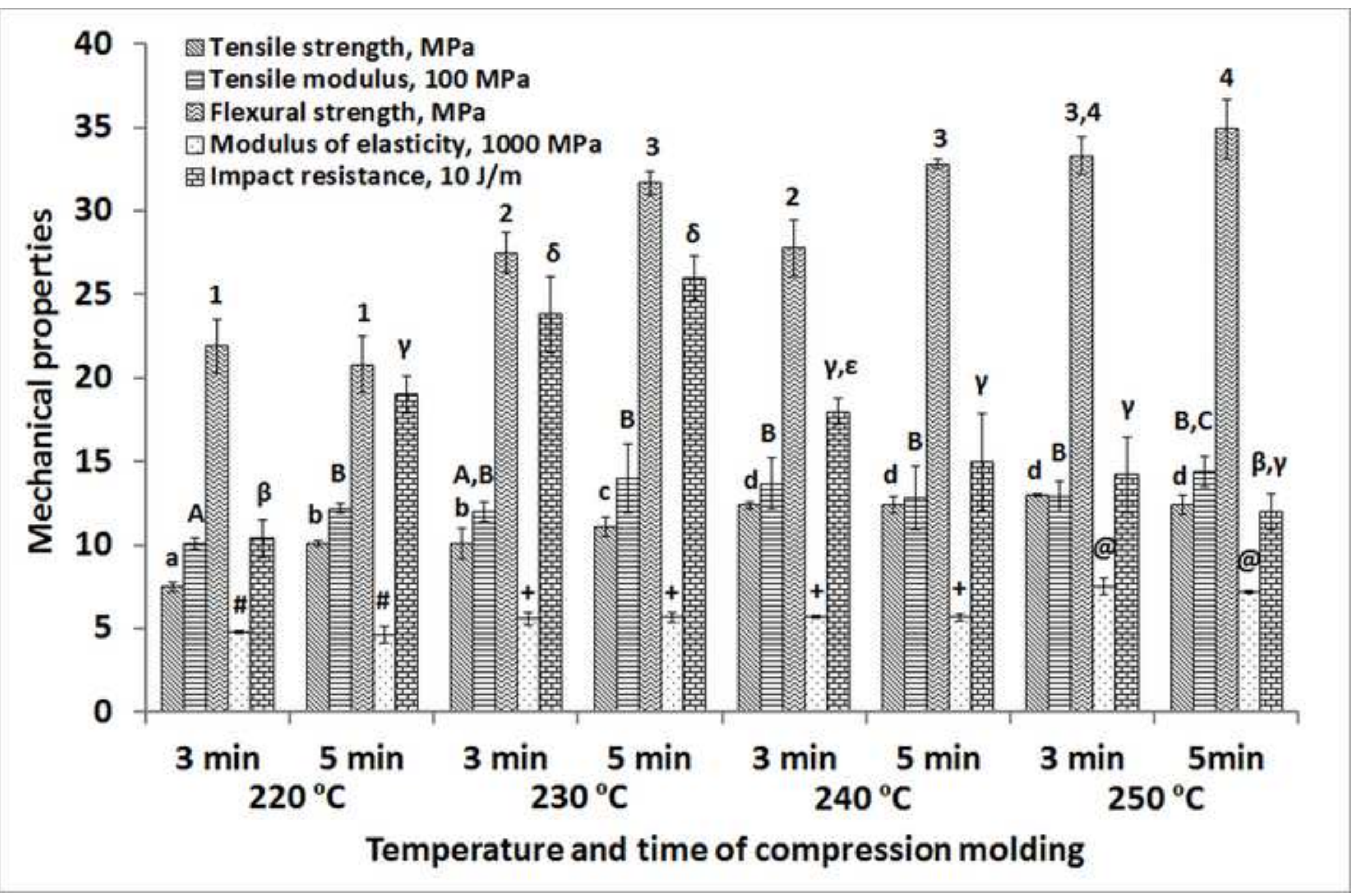



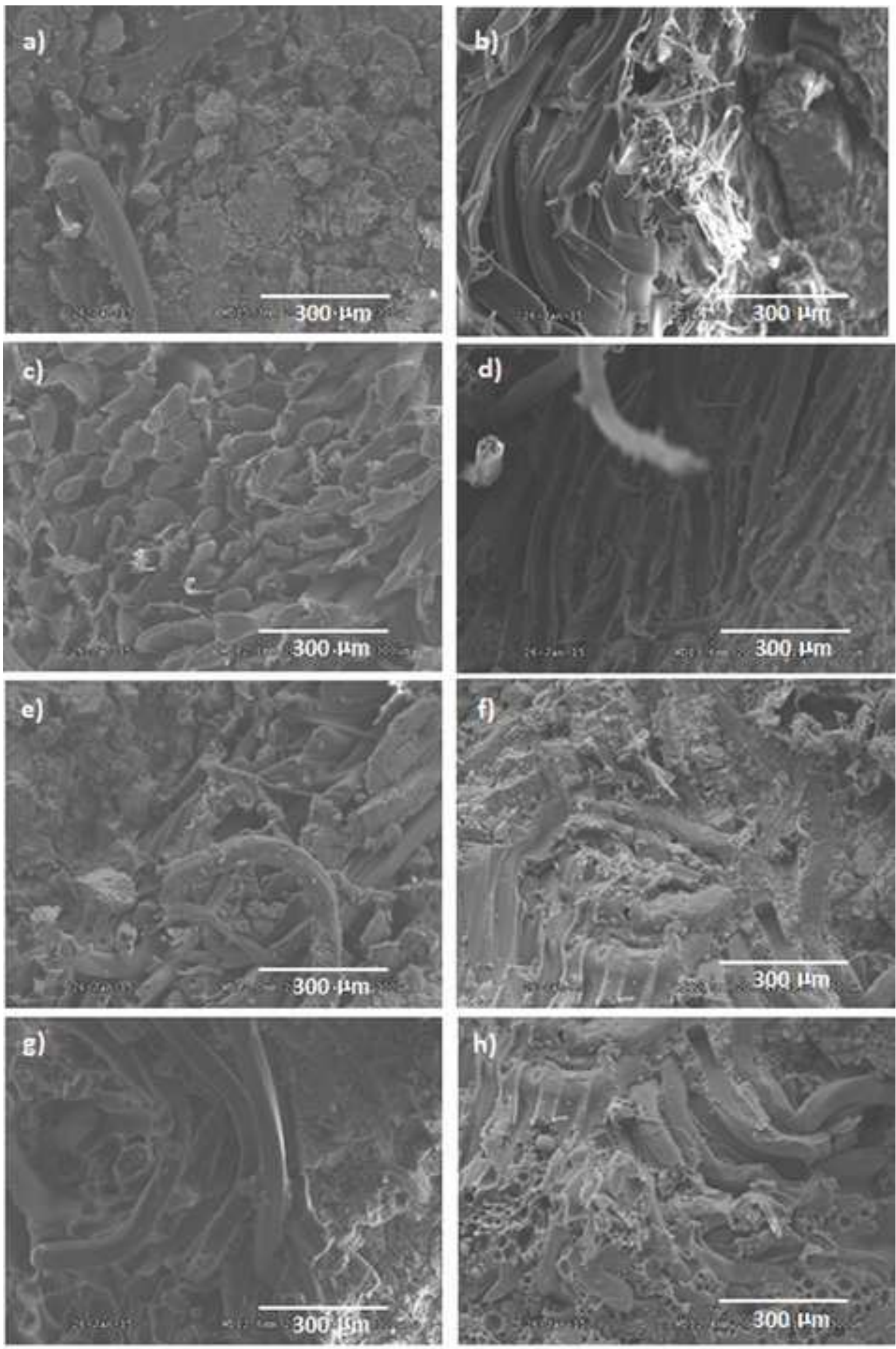


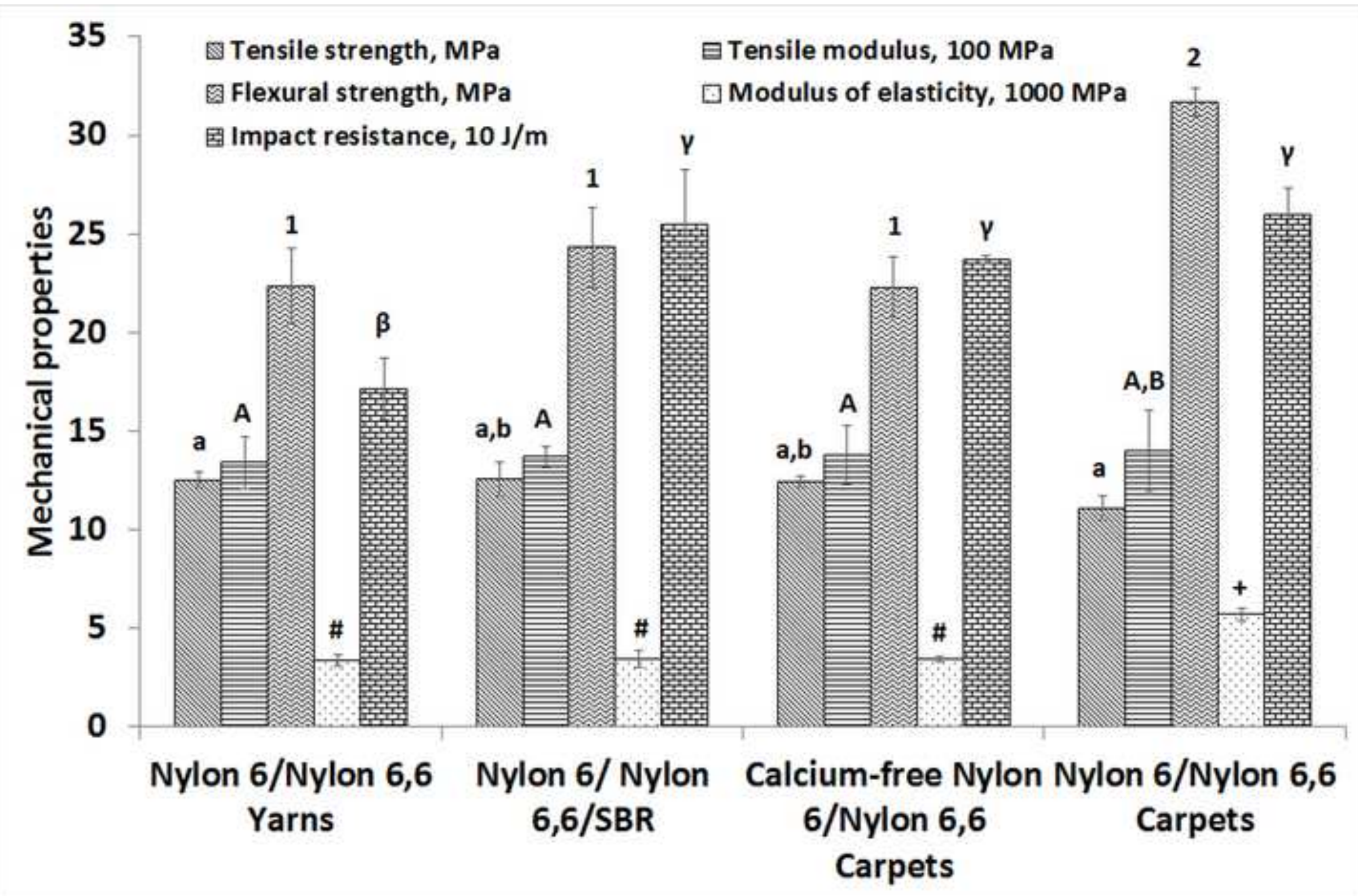


a)
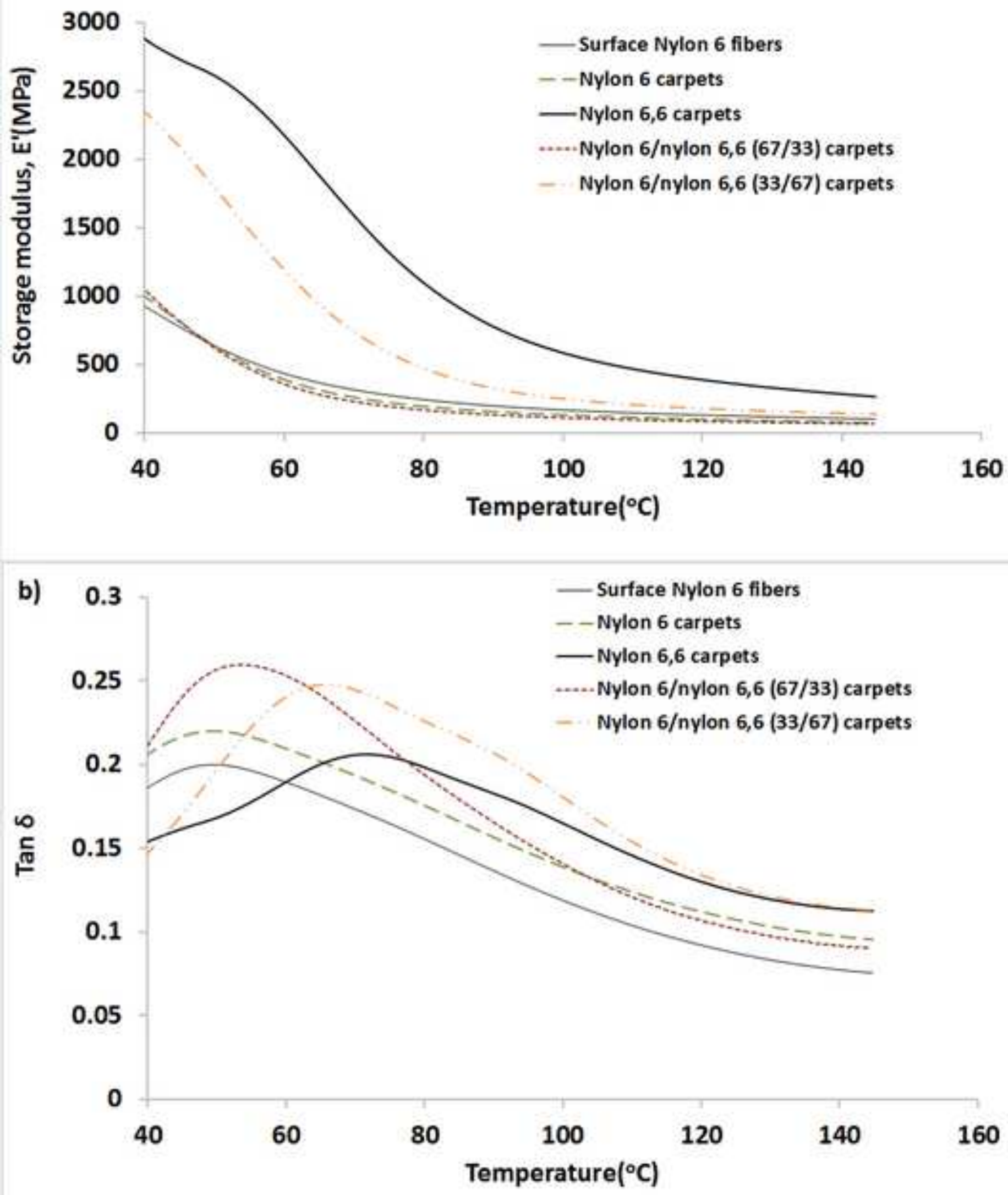

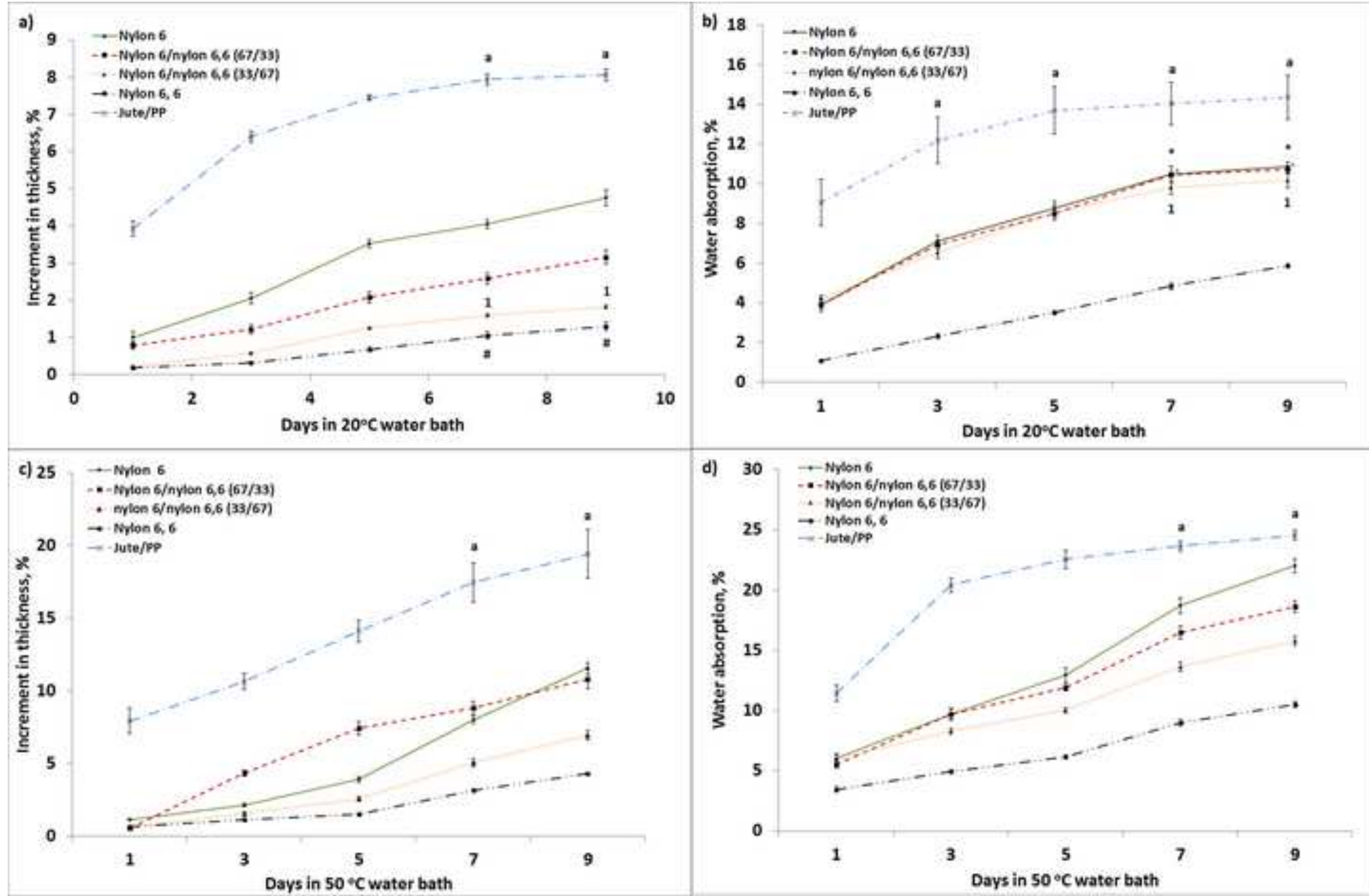


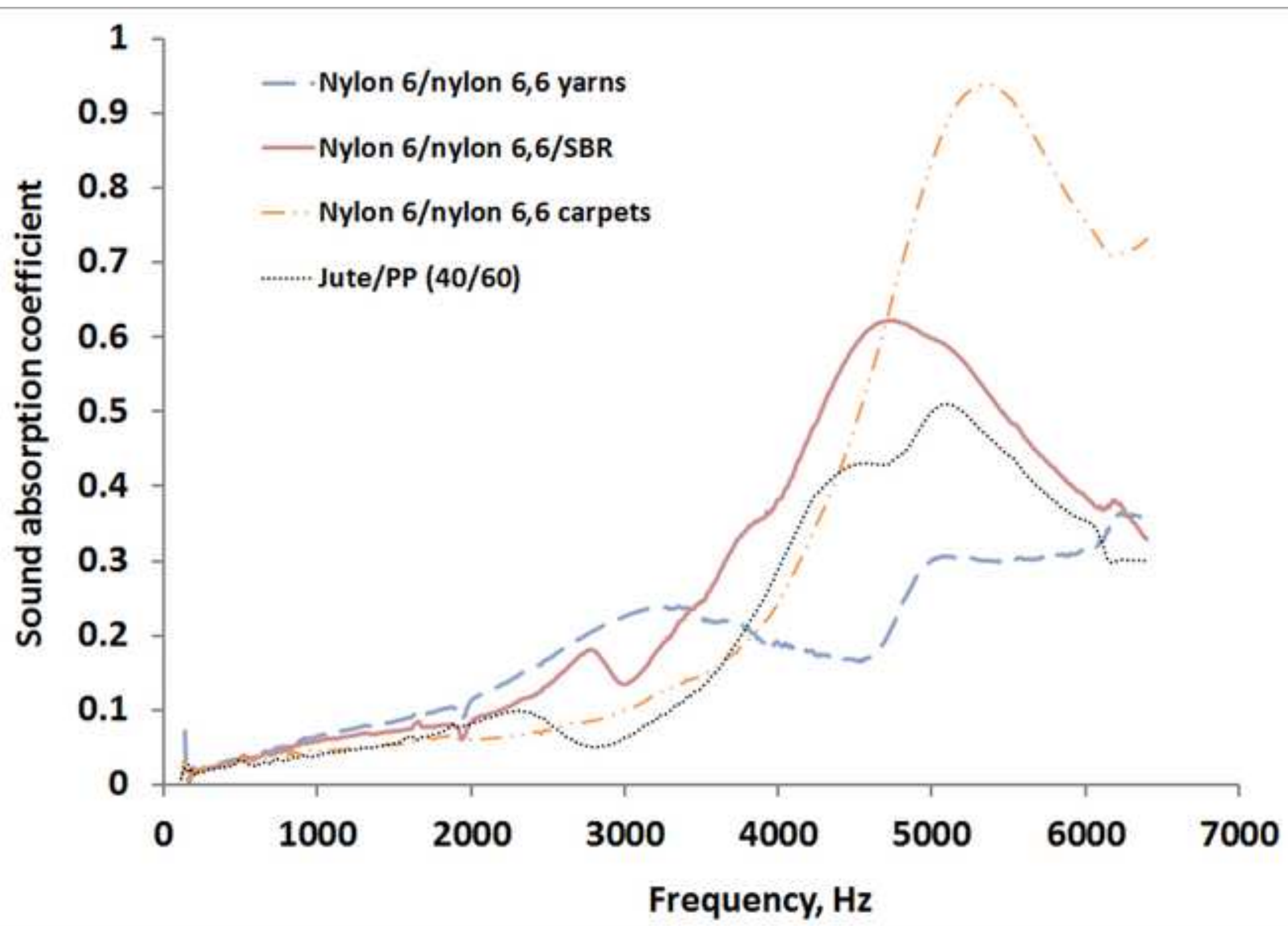




\title{
Compression Molded Composites from Discarded Nylon 6/Nylon 6,6 Carpets for
}

\section{Sustainable Industries}

\author{
Gangwei Pan $^{1,2}$, Yi Zhao ${ }^{2}$, Helan $\mathrm{Xu}^{2}$, Xiuliang Hou ${ }^{1}$, Yiqi Yang ${ }^{1,2,3,4^{*}}$ \\ ${ }^{1}$ Key Laboratory of Science and Technology of Eco-Textiles, Ministry of Education, \\ Jiangnan University, Wuxi 214122, China \\ ${ }^{2}$ Department of Textiles, Merchandising \& Fashion Design, University of \\ Nebraska-Lincoln, Lincoln, NE, 68583-0802, USA \\ ${ }^{3}$ Department of Biological Systems Engineering, University of Nebraska-Lincoln, \\ Lincoln, NE, 68583-0802, USA \\ ${ }^{4}$ Nebraska Center for Materials and Nanoscience, University of Nebraska-Lincoln, \\ Lincoln, NE, 68583-0802, USA \\ * Corresponding author: Yiqi Yang
}

Phone: 402-472-5197; Fax: 402-472-0640; Email: yyang2@unl.edu

Gangwei Pan Email: pangangwei@gmail.com

Yi Zhao Email: huahuati87@gmail.com

Helan Xu Email: $\underline{\text { hxu14@unl.edu }}$

Xiuliang Hou Email: houxiuliang@163.com 


\section{ABSTRACT}

Discarded carpets with high amount of petroleum-based fibers are usually disposed in landfills, leading to waste of high value petro-polymers and environmental pollution. A novel method to reuse nylon carpet targeting environmental protection and material saving was developed. Recent studies showed that melt blended nylon carpet composites by screw extruder had low mechanical properties and disqualified carpet composites in transportation and construction industries. In this research, compression molded composites from discarded nylon 6/nylon 6,6 carpets had good sound absorption, mechanical properties and water stability. As compared with jute/PP composites, the compression molded composites from nylon 6/nylon 6,6 carpets had up to $40 \%, 59 \%, 124 \%$ and $32 \%$, higher sound absorption, flexural strength, elastic modulus and impact resistance, respectively. Unshredded nylon 6,6 carpet yarns and styrene-butadiene-rubber/calcium-carbonate binders in carpets reinforced nylon 6 and polypropylene, and thus made the composites strong. Styrene-butadiene-rubber particles and multiple interfaces in the multi-component composites endowed compression molded nylon 6/nylon 6,6 carpet composites with good sound absorption. Developing compression molded carpet composites with good mechanical properties and sound absorption provides a new method of reusing carpets.

Keywords: Nylon carpets reuse; Thermoplastic composites; Sound absorption; Compression molding 


\section{Introduction}

Currently, petroleum-based materials are widely used in automotive and construction industries due to their good mechanical properties, low density and low cost. Non-degradable petro-materials, such as polyamide, polypropylene, and polyurethanes, are largely consumed in vehicle manufacturing and indoor finishing, including car doors (Carlson and Nelson, 1996), body panels (Alcock et al., 2008), car seats (Santos et al., 2007), and indoor partition boards (Liu et al., 2012). Polyamides share around $10.7 \%$ market of automobile materials and have an annual consumption of 1,000,000 tons in automotive industry ( $\mathrm{Lu}$ et al., 2014). However, potential increase in prices of crude oil and more strict regulations towards environmental pollution (Koronis et al., 2013) forced material industries to actively seek environmentally friendly and economically feasible approaches to decrease usage of petroleum-based products (Correia et al., 2011), substitute (Zhao, et al., 2015a), recycle (Lopes et al., 2014) or reuse (Zhao et al., 2015b) petro-products.

Discarded carpet has been the solid waste with the largest amounts. There are 4-6 million tons carpets disposed in landfills worldwide annually (Mihut et al., 2001). Among waste carpets, $65 \%$ of carpets are nylon carpets containing thermoplastic polyamide yarns with selling price as high as $\$ 5.5$ per $\mathrm{kg}$ (Wang and Zhao, 2006) and poorly degradable styrene-butadiene-rubber (SBR) (Subramanian, 2000; Wang, 2010). Reusing waste nylon carpets could save new petro-based polymers, reduce environmental pollution, and therefore promote sustainability of material industries.

Being composed mainly of thermoplastics, nylon carpets could be reused via melt 
blending. Compared to other reusing methods, such as depolymerization, polyamide extraction, incineration and fiber separation, melt blending is preferred due to its low cost, easy operation and high reuse rate. Melt blending of nylon carpets requires no separation of fibers from carpets, because the shredded carpets were directly extruded at about $250-350{ }^{\circ} \mathrm{C}$ (Mihut et al., 2001; David et al., 1997), at which, surface nylon and backing polypropylene yarns melted, while $\mathrm{SBR} / \mathrm{CaCO}_{3}$ as carpet binders might be damaged or decomposed (Radhakrishnan et al., 2007). In addition, the extruded composites from shredded nylon carpets had low mechanical properties due to lack of fiber reinforcement, and thus were not qualified for industrial applications. Nylon carpet yarns, as fiber reinforcement, could effectively increase toughness, durability and shrinkage of concrete (Wang et al., 2000), or increase mechanical properties of polypropylene sheets (Abraham and George, 2009). Thermoplastic nylon was also reinforced by high performance fibers and natural fibers, such as glass fibers (Khondker et al., 2005), carbon fibers (Ishak and Berry, 1994), kevlar fibers, kenaf, flax, hemp, sisal, and jute (Ozen et al., 2013) for manufacturing high-strength or light-weight composites. However, there has been no report regarding developing nylon 6 composites reinforced by nylon 6,6 yarns till now. Besides, function of SBR and $\mathrm{CaCO}_{3}$ in melt blended carpet composites have not been investigated.

In this research, we developed nylon 6,6 yarns and $\mathrm{SBR} / \mathrm{CaCO}_{3}$ particles reinforced nylon 6/polypropylene composites via compression molding discarded nylon 6/nylon 6,6 carpets. Nylon 6,6 has higher melting temperature than nylon 6, and therefore could preserve their fiber morphology for better reinforcement, when the pressing 
temperature was between melting temperatures of nylon 6 and nylon 6,6. SBR particles (6-10 wt\% of carpet weight) in the carpets could be prevented from damaging or decomposing when compression molded at the melting temperature (around $220{ }^{\circ} \mathrm{C}$ ) of nylon 6 (Zhang et al., 2005). SBR with low density has high toughness and ability to absorb energy because of its high damping coefficient (Schopp, 2014; Gauthier et al., 2004). In addition, nylon 6 or nylon 6,6 yarns have characteristics of high abrasion resistance, thermal stability, and deformation resistance. Therefore, the composites from nylon 6/nylon 6,6 waste carpets should have good mechanical properties and sound absorption.

\section{Experimental}

This section is organized as follows: first, composition analysis of nylon carpets and fabrication of composites are described. The characterizations of the nylon 6/nylon 6,6 carpets composites are then provided in detail.

\subsection{Materials}

Both nylon 6 and nylon 6,6 loop pile carpets were purchased from Carpet Land Inc., Lincoln, NE. There are four basic materials in nylon 6 or nylon 6,6 carpets: nylon 6 or nylon 6,6, polypropylene (PP), styrene butadiene (SBR) and calcium carbonate $\left(\mathrm{CaCO}_{3}\right)$. Hydrochloric acid $(\mathrm{HCl})(37 \%)$ was purchased from EMD Chemicals Inc., Gibbstown, NJ. Jute fibers were purchased from Bast Fibers LLC (Cresskill, NJ) and had an average fineness of 32 denier, tensile strength of $312 \mathrm{MPa}$, breaking elongation of $1.4 \%$ and Young's modulus of $24.3 \mathrm{GPa}$.

\subsection{Composition analysis of nylon carpets}



were taken on a on a Nicolet 380 (Thermo-Nicolet, Waltham, MA) spectrophotometer through the diffuse reflectance technique from 400 to $4000 \mathrm{~cm}^{-1}$ with a resolution of 4 $\mathrm{cm}^{-1}$ and 64 scans. The FTIR spectra obtained were analyzed using OMNIC software (Thermo Electron Corp., Waltham, MA). Surface nylon yarns and backing PP yarns were disconnected from the nylon 6 or nylon 6,6 carpets. Adhesives of $\mathrm{SBR} / \mathrm{CaCO}_{3}$ particles were separated from nylon yarns on a Louet laboratory scale carding machine. To remove $\mathrm{CaCO}_{3}$, carpets were soaked in $1 \% \mathrm{HCl}$ for $24 \mathrm{~h}$ and then rinsed in distilled water for $2 \mathrm{~h}$. After dried at $50{ }^{\circ} \mathrm{C}$ for $12 \mathrm{~h}$ and balanced in a sealed desiccator for $2 \mathrm{~h}$, calcium-free carpets were weighed. The weight ratio of nylon 6: $\mathrm{CaCO}_{3}: \mathrm{SBR}: \mathrm{PP}$ in the carpets was $38: 40: 12: 10$; weight ratio of nylon 6,6: $\mathrm{CaCO}_{3}: \mathrm{SBR}: \mathrm{PP}$ was 40:40:12:8.

\subsection{Thermal analysis}

Melting temperatures of nylon 6, nylon 6,6 and backing PP yarns were measured using a differential scanning calorimetry (DSC). About $15 \mathrm{mg}$ of each type of yarns were placed in aluminum pans and the DSC Mettler Toledo D822e (Mettler Toledo Inc., Columbus, $\mathrm{OH}$ ) was operated at a heating rate of $10{ }^{\circ} \mathrm{C} / \mathrm{min}$ from $50{ }^{\circ} \mathrm{C}$ to $280{ }^{\circ} \mathrm{C}$ under nitrogen atmosphere. The obtained DSC thermogram was analyzed to determine the melting temperature of nylon 6, nylon 6,6 and PP filaments. SBR and calcium carbonate do not have melting temperature due to their non-thermoplasticity. Melting points of the nylon 6, nylon 6,6 and PP were around 220, 260, and $160{ }^{\circ} \mathrm{C}$, 
respectively.

\subsection{Fabrication of compression molded composites}

The nylon 6 and nylon 6,6 carpets were placed alternatively between two aluminum sheets and pressed in a laboratory-scale press (Carver, Inc., Wabash, IN) preheated to desired temperatures. Since melting temperatures of nylon 6 and nylon 6,6 were around $220{ }^{\circ} \mathrm{C}$ and $260{ }^{\circ} \mathrm{C}$, respectively, temperatures of $220,230,240$ and $250{ }^{\circ} \mathrm{C}$ were used to press the composites of nylon carpets, while the holding time periods were 3 and $5 \mathrm{~min}$, respectively. The compression pressure was $10 \mathrm{MPa}$. Different numbers of nylon 6,6 carpet and nylon 6 carpet layers were prepared to obtain final composites with different ratios of nylon 6 and nylon 6,6. Thickness of the obtained composites was $4.5 \pm 0.08 \mathrm{~mm}$.

To investigate effect of $\mathrm{CaCO}_{3}$ in the compression molded composites from nylon 6/nylon 6,6 carpets (nylon 6/nylon 6,6 composites), carpets were treated in $1 \% \mathrm{HCl}$ for $24 \mathrm{~h}$ and rinsed in water to remove calcium carbonate. After dried at $50{ }^{\circ} \mathrm{C}$ for 12 h, carpets without $\mathrm{CaCO}_{3}$ were obtained. To study SBR effect, polypropylene backing yarns were removed from calcium free carpets, while the separated nylon 6/nylon 6,6 carpet yarns were prepared for $0 \mathrm{wt} . \%$ SBR samples as controls.

Jute/PP composites containing 40 wt.\% of jute fibers had good mechanical properties (Zou et al., 2010). Thus, jute/PP (40/60) composites were compression molded at $180{ }^{\circ} \mathrm{C}$ for 10 min as a control with the same density and thickness as carpet composites. Polypropylene carpets were also compression molded at $180{ }^{\circ} \mathrm{C}$ for $10 \mathrm{~min}$ as another control with the same density. 


\subsection{Tensile and flexural properties of compression molded composites}

Tensile tests were performed on an MTS machine QTest10 (MTS Corporation, Eden Prairie, MN). Procedures in ASTM D638-03 were followed. Length of the samples was $165 \mathrm{~mm}$, width of the sample was $19 \mathrm{~mm}$, and gage length was $115 \mathrm{~mm}$. Crosshead speed was $5 \mathrm{~mm} / \mathrm{min}$. Flexural tests were carried out on an MTS QTest10 tester following procedure of ASTM D790-03, sample size was $7.6 \mathrm{~cm} \times 20.3 \mathrm{~cm}$ with $15.2 \mathrm{~cm}$ support length, load cell was $500 \mathrm{~N}$, and the crosshead speed was $10 \mathrm{~mm} / \mathrm{min}$. Offset yield load was recorded at $2.0 \mathrm{~mm}$.

\subsection{Impact resistance of compression molded composites}

Impact resistance test was performed on a Plastic Impact Tester by Tinius Olsen model 66 (Tinius Olsen, Horsham, PA) using procedure ASTM D256-03 (ASTM, 2003a). Sample size was $63.5 \mathrm{~mm} \times 10.2 \mathrm{~mm}$. The notch was cut perpendicular to the cross section.

\subsection{Dynamic mechanical analysis}

The viscoelastic properties of the composites were measured by a dynamic mechanical analyzer DMA Q800 (TA Instrument Inc., New Castle, DE) according to ASTM D4065 standard. The test was carried out by heating the samples from 40 to $145{ }^{\circ} \mathrm{C}$ at a rate of $5{ }^{\circ} \mathrm{C} / \mathrm{min}$. The samples were tested in a dual cantilever mode at an oscillating amplitude of $15 \mathrm{~mm}$ and frequency of $1 \mathrm{~Hz}$.

\subsection{Morphology}

Cross-sections of the compression molded composites from nylon 6 carpets and nylon 6,6 carpets were observed using a variable pressure scanning electron 
microscope (VPSEM) Hitachi S3000N (Hitachi, Tarrytown, NY). Samples were sputter coated with gold palladium before observing under the SEM. Magnification of SEM images was $150 \times$.

\subsection{Water Stability}

The swelling and water absorption were conducted according to ASTM D 570 standard. Swelling was measured in the thickness direction of the composites. A piece of carpet with dimension of about $3 \mathrm{~cm} \times 3 \mathrm{~cm}$ was immersed in $20{ }^{\circ} \mathrm{C}$ and $50{ }^{\circ} \mathrm{C}$ water for 1, 3, 5, 7 and 9 days. After removal from the water, the samples were dried by patting with a towel before measuring thickness and weight. The data reported are average values obtained from five separate samples.

\subsection{Sound absorption}

Sound absorption of the composites were determined according to ASTM standard E1050-98 on a Bruel \& Kjaer impedance tube (type 4206 A) (Bruel \& Kjaer, Norcross, GA) at 0 to $6.5 \mathrm{kHz}$. Three samples with diameter of $63 \mathrm{~mm}$ from different composites were tested for the sound absorption and the average readings were used to plot the absorption coefficient curves.

\subsection{Statistical analysis}

Data generated was analyzed using Tukey's multiple-pair wise comparison using SAS program (SAS Institute, Raleigh, NC). A significance level of $\alpha=0.05$ was considered as statistically significant. In each figure, data points without significant differences were marked with same letters, numbers or symbols.

\section{Results and discussion}


To fabricate compression molded composites from waste nylon 6 and nylon 6,6

carpets, effects of concentration of nylon 6,6 carpets, solid SBR and $\mathrm{CaCO}_{3}$, and hot

pressing conditions on mechanical properties of carpet composites were studied.

Dynamic mechanical properties, water stability and sound absorption of the carpet

composites were also evaluated. Comparisons of the carpet composites and jute/PP

composites in terms of mechanical properties, water stability and sound absorption

were finally carried out.

3.1 Effect of concentration of nylon 6,6 carpets on the mechanical properties of the compression molded composites from nylon 6/nylon 6,6 carpets

Compression molded composites from nylon 6/nylon 6,6 carpets (nylon 6/nylon 6,6 composites) had substantially higher mechanical properties than those from either nylon 6 carpets or nylon 6,6 carpets. Compression molded composites from single nylon 6 carpets or nylon 6,6 carpets fabricated at their respective melting temperatures had no fiber reinforcement and therefore showed comparatively low mechanical properties as indicated in Fig. 1. Increasing concentration of nylon 6,6 carpets from 0 to $33 \%$ substantially increased impact resistance of molded composites, and slightly increased their tensile properties. Further increasing concentration of nylon 6,6 carpets to $66 \%$ increased flexural strength, elastic modulus, and impact resistance of the final compression molded composites by $57 \%, 262 \%$ and $72 \%$, respectively, and slightly increased tensile strength and tensile modulus. Increasing concentration of nylon 6,6 carpets from $33 \%$ to $66 \%$ increased concentration of nylon 6,6 fibers from $13.2 \%$ to $26.4 \%$ in the compression molded composites. Therefore, 
the unmelted nylon 6,6 fibers as reinforcement in the nylon 6/nylon 6,6 composites enhanced mechanical properties.

\section{Fig. 1}

3.2 Effect of hot pressing temperature and holding time on mechanical properties of the compression molded composites from nylon 6/nylon 6,6 carpets

As shown in Fig. 2, prolonging holding time from $3 \mathrm{~min}$ to $5 \mathrm{~min}$ at $220{ }^{\circ} \mathrm{C}$ and $230{ }^{\circ} \mathrm{C}$ increased tensile strength, tensile modulus, flexural strength, elastic modulus, and impact resistance of the nylon 6/nylon 6,6 composites. Increasing holding time from $3 \mathrm{~min}$ to $5 \mathrm{~min}$ at $240{ }^{\circ} \mathrm{C}$ and $250{ }^{\circ} \mathrm{C}$ decreased impact resistance of the compression molded composites from two types of nylon carpets. The nylon 6/nylon 6,6 composites had higher impact resistance at hot pressing temperature of $230{ }^{\circ} \mathrm{C}$; while the nylon 6/nylon 6,6 composites had higher tensile and flexural strength at hot pressing temperature of $250{ }^{\circ} \mathrm{C}$.

\section{Fig. 2}

Increasing compression molding temperature and holding time increased tensile and flexural strength of the nylon 6/nylon 6,6 composites, probably due to increased adhesion between fiber reinforcement and matrix. As shown in Fig. 3, either increasing compression temperature from $220{ }^{\circ} \mathrm{C}$ to $250{ }^{\circ} \mathrm{C}$ for the same holding time ( 3 or $5 \mathrm{~min}$ ) or increasing holding time from $3 \mathrm{~min}$ to $5 \mathrm{~min}$ at the same compression temperature $\left(230,240\right.$, or $250{ }^{\circ} \mathrm{C}$ ) improved combination of melted matrix (nylon 6) and unmelted fiber reinforcement (nylon 6,6). It is probably because increasing compression temperature increased softness of nylon 6,6 yarns. Since surface nylon 
6,6 yarns had loop piles, unmelted nylon 6,6 yarns could be observed oriented randomly in the composites. SBR with good damping property was probably damaged under high temperature, resulting in decreased toughness and impact resistance of the final composites.

Fig. 3

3.3 Effect of $\mathrm{SBR}$ and $\mathrm{CaCO}_{3}$ on mechanical properties of the nylon 6/nylon 6,6 carpet composites

As shown in Fig. 4, SBR increased impact resistance of the composites from nylon 6/nylon 6,6 carpet yarns, and did not decrease their tensile and flexural properties. $\mathrm{CaCO}_{3}$ increased flexural strength and elastic modulus, slightly increased tensile modulus and slightly decreased tensile strength of the carpet composites. SBR has good toughness and could absorb more impact energy ( $\mathrm{Li}$ and Nji, 2007). Therefore, the compression molded composites from nylon 6/nylon 6,6/SBR had better impact resistance than that from nylon 6/nylon $6,6 . \mathrm{CaCO}_{3}$ particles have high stiffness and thus could increase tensile and flexural modulus of composites. However, $\mathrm{CaCO}_{3}$ particles decreased interaction between reinforcement and matrix, thus decreased tensile strength of the composites (Qiu et al., 2000). Flexural strength is different from tensile strength, and is affected by surface stiffness of materials. Therefore, adding $\mathrm{CaCO}_{3}$ could improve flexural strength.

Fig. 4

3.4 Comparisons of the mechanical properties of the compression molded composites from nylon 6/nylon 6,6 carpets, PP carpets, and jute/PP 
Table 1 displays mechanical properties of the compression molded composites from nylon 6/nylon 6,6 carpets, PP carpets and jute/PP. Compared to the compression molded composites from PP carpets, the nylon 6/nylon 6,6 composites had 12\%, $169 \%, 309 \%$, and $48 \%$ higher tensile strength, flexural strength, elastic modulus, and impact resistance, but $22 \%$ lower tensile modulus, respectively. It is probably because the nylon 6/nylon 6,6 composites contain $13 \%$ more fiber reinforcement than the PP carpet composites. In addition, nylon 6/PP matrix had higher elasticity than PP matrix. However, reinforcing nylon 6,6 yarns with loop piles were not aligned straightly in the nylon 6/nylon 6,6 composites, and thus cannot substantially strengthen tensile strength of the compression molded composites. Compared to the jute/PP composites, the nylon 6/nylon 6,6 composites had 59\%, 124\%, and 32\% higher flexural strength, elastic modulus, and impact resistance, but similar tensile modulus and lower tensile strength. It is probably because nylon 6,6 yarns had higher tensile strength than jute fibers. Also, nylon 6 and PP as matrix have better flexural properties than only PP. SBR had high damping property and thus endowed the nylon 6/nylon 6,6 carpet composites with good capability of absorbing impact energy. However, fiber reinforcement with loop piles in the nylon 6/nylon 6,6 composites did not effectively share tensile strength when stretching. Therefore, nylon 6/nylon 6,6 composites had higher flexural properties and impact resistance but lower tensile properties than jute/PP composites.

\section{Table 1}

\subsection{Dynamic mechanical analysis}


Nylon 6,6 yarns as reinforcement increased elastic modulus and damping properties of the nylon 6/nylon 6,6 composites. Dependence of storage modulus (E') and loss factor $(\tan \delta)$ of the nylon 6/nylon 6,6 composites on temperature are depicted in Fig. 5. Increasing the amount of nylon 6,6 carpets increased storage modulus of the nylon 6/nylon 6,6 composites, indicating increased elasticity of the final composites. This was in accordance with the changes in the previous tensile properties of the nylon 6/nylon 6,6 composites. Increasing temperature decreased storage modulus of the compression molded composites with different ratios of nylon 6 and nylon 6,6 carpets due to softening of nylon fibers and matrix. Compared to the compression molded composites from nylon 6 carpets, substantial decrease in storage modulus of the composites reinforced by nylon 6,6 carpets occurred at higher temperature due to the high glass transition temperature of nylon 6,6 , indicating better thermal stability of compression molded composites with reinforcement of nylon 6,6 .

Higher value of $\tan \delta$ indicates better damping property. Compression molded composites from nylon 6 carpets had higher $\tan \delta$ than pure nylon 6 board due to incorporation of solid SBR in carpets. SBR is capable of transforming sound energy into heat via vibration and friction of molecular chains, and therefore could increase sound absorption of materials. Compared to compression molded composites from nylon 6 carpets or nylon 6,6 carpets, compression molded composites from nylon 6/nylon 6,6 (67/33) carpets and nylon 6/nylon 6,6 (33/67) carpets had higher tan $\delta$, due to high interfacial friction between nylon 6 matrix and nylon 6,6 reinforcement. The hot-pressed composites reinforced by nylon 6,6 yarns showed high $\tan \delta$, 
indicating their good damping properties and consequently good sound absorption.

\section{Fig. 5}

\subsection{Water stability}

As shown in Fig. 6, nylon 6/nylon 6,6 composites had good stability in water at 20 and $50{ }^{\circ} \mathrm{C}$. With prolonged immersing days in $20{ }^{\circ} \mathrm{C}$ water from 1 day to 9 days, all the nylon 6/nylon 6,6 composites with different combination ratios had substantially lower increment of thickness and water absorption than jute/PP composites. Among the nylon 6/nylon 6,6 composites with different combination ratios, compression molded composites from nylon 6,6 carpets and nylon 6/nylon 6,6 (33/67) carpets showed comparative higher water stability. This was in accordance with results from Fuzek's research (Fuzek, 1985). On the 9th day, compression molded composites from nylon 6,6 carpets had $1.3 \pm 0.4 \%$ increment in thickness and $5.8 \pm 0.3 \%$ increment in water absorption, respectively, while jute/PP composites had $8.1 \pm 0.6 \%$ increment in thickness and $14.3 \pm 4.4 \%$ increment in water absorption, respectively.

In water at $50{ }^{\circ} \mathrm{C}$, compression molded composites from nylon 6,6 carpets still showed much lower increment in thickness and water absorption compared to jute/PP composites during the 9 days. Jute fibers are hydrophilic and swell easily in wet condition (Nagarajan et al., 2013), leading to increased water absorption and thickness of jute reinforced PP composites. In the nylon carpets, nylon 6, nylon 6,6 fibers and SBR solids had substantially lower water absorption than jute fibers, while $\mathrm{CaCO}_{3}$ as one type of desiccant could absorb moisture. However, in the carpet composites, $\mathrm{CaCO}_{3}$ particles were discontinued and enclosed by the hydrophobic SBR, and thus 
were not affected by water. Therefore, the nylon 6/nylon 6,6 composites had satisfactory water stability at room temperature and high temperature.

Fig. 6

\subsection{Sound absorption}

Solid SBR endowed nylon 6/nylon 6,6 composites with good sound absorption. As shown in Fig. 7, compression molded composites from nylon 6/nylon 6,6 carpet yarns had substantially lower sound absorption compared to the compression molded composites from nylon 6/nylon 6,6 yarns and SBR. The composites with SBR had good sound absorption at frequency ranging from 3000 to $4500 \mathrm{~Hz}$, but the composites without SBR did not. Solid SBR with high damping coefficient could absorb sound wave efficiently and thus endowed compression molded composites with higher sound absorption (Najib et al., 2011).

Compared to jute/PP composite, compression molded composites from nylon 6/nylon 6,6 (33/67) carpets had similar and substantially higher sound absorption at frequency lower than $2000 \mathrm{~Hz}$ and higher than $4500 \mathrm{~Hz}$. Multiple interfaces in the multi-component composites endowed compression molded nylon 6/nylon 6,6 carpet composites with good sound absorption (Zhao et al., 2010). Sound absorption at frequency lower than $2000 \mathrm{~Hz}$ and ranging from 3000 to $5000 \mathrm{~Hz}$ are desired for some automotive and construction materials because these frequency zones correspond with noise on high way (Zou et al., 2010; Ouis, 2001), in airport, grinding or welding workshop (Siller et al., 2010). The nylon 6/nylon 6,6 composites could be utilized as sound absorption panels for inside applications, such as automotive interior, inside construction composites or road construction materials, and therefore could be 
promising in transportation and construction industries.

\section{Fig. 7}

\section{Conclusions}

Compression molded composites from discarded nylon 6/nylon 6,6 carpets had good sound absorption, mechanical properties and water stability. SBR particles substantially improved sound absorption and impact resistance, and did not decrease tensile and flexural properties of the compression molded composites from nylon 6/nylon 6,6 carpet yarns. $\mathrm{CaCO}_{3}$ particles could enhance elastic modulus, flexural strength and tensile modulus, but decrease tensile strength of the compression molded carpet composites. Multiple interfaces in the multi-component carpet composites endowed compression molded nylon 6/nylon 6,6 carpet composites with good sound absorption. Compared to jute/PP (40/60) composites, the nylon 6/nylon 6,6 composites showed 40\%, 59\%, 124\%, 32\%, and 9\% higher sound absorption at medium/high frequency, flexural strength, elastic modulus, impact resistance and water stability, respectively, and 55\% and $17 \%$ lower tensile strength and modulus, respectively. Therefore, compression molded composites from discarded nylon 6/nylon 6,6 carpets have good composite performances and show potential for transportation and construction industries. This work provides a novel method of reusing carpets and elucidated the advantage of this method.

\section{Acknowledgements}

This research was financially supported by Nebraska Environmental Trust (NET project 12-129), National Institute of Food and Agriculture of U.S. Department of 
Agriculture (Multi-State Project S1054 (NEB 37-037) and USDA Hatch Act), and the Agricultural Research Division at the University of Nebraska-Lincoln. Yi and Gangwei are grateful to the China Scholarship Council for the financial support. The authors appreciate support from Graduate Student Innovation Plan of Jiangsu Province (CXZZ13_0751) and the Fundamental Research Funds for the Central Universities (JUDCF13021) for Gangwei Pan and John and Louise Skala Fellowship at the University of Nebraska-Lincoln for Yi Zhao.

\section{References}

Abraham, T.N., George, K.E., 2009. Studies on recyclable nylon-reinforced PP composites: effect of fiber diameter. J. Thermoplast. Compos. Mater. 22(1). 5-20.

Alcock, B., Cabrera, N.O., Barkoula, N.M., Wang, Z., Peijs, T., 2008. The effect of temperature and strain rate on the impact performance of recyclable all-polypropylene composites. Compos. Part B-Eng. 39(3): 537-547.

Carlson, E., Nelson, K., 1996. Nylon under the hood: a history of innovation. Automot. Eng. 104(12), 84-89.

Correia, J.R., Almeida, N.M., Figueira, J.R., 2011. Recycling of FRP composites: reusing fine GFRP waste in concrete mixtures. J. Clean. Prod. 19(15), 1745-1753.

David, D.J., Dickerson, J.L., Sincock, T.F., 1997. Thermoplastic composition and method for producing thermoplastic composition by melt blending carpet. U.S. Paten. No. 5,591,802.

Fuzek, J.F., 1985. Absorption and desorption of water by some common fibers. Ind. Eng. Chem. Prod. Res. Dev. 24(1), 140-144. 
Gauthier, C., Reynaud, E., Vassoille, R., 2004. Ladouce-Stelandre L. Analysis of the non-linear viscoelastic behavior of silica filled styrene butadiene rubber. Polymer. $45(8), 2761-2771$.

Ishak, Z.A., Berry, J.P., 1994. Hygrothermal aging studies of short carbon fiber reinforced nylon 6.6. J. Appl. Polym. Sci. 51(13), 2145-2155.

Khondker, O.A., Leong, K.H., Herszberg I., Hamada H., 2005. Impact and compression-after-impact performance of weft-knitted glass textile composites. Compos. Part A-Appl. S 36(5), 638-648.

Koronis, G., Silva, A., Fontul, M., 2013. Green composites: a review of adequate materials for automotive applications. Compos. Part B-Eng. 44(1), 120-127.

Li, G.Q., Nji, J., 2007. Development of rubberized syntactic foam. Compos. Part A-Appl. S 38(6), 1483-1492.

Liu, W., Zhao, H.B., Inoue, Y.K.; Wang, X., Bradford, P.D., Kim, H., Qiu, Y.P., Zhu, Y.T., 2012. Poly (vinyl alcohol) reinforced with large-diameter carbon nanotubes via spray winding. Compos. Part A-Appl. S 43 (4), 587-592.

Lopes, D., Ferreira, M.J., Russo, R., Dias, J.M., 2014. Natural and synthetic rubber/waste-EVA (Ethylene-Vinyl Acetate) composites for sustainable application in the footwear industry. J. Clean. Prod. 92, 230-236.

Lu, Y., Broughton, J., Winfield, P., 2014. A review of innovations in disbonding techniques for repair and recycling of automotive vehicles. Int. J. Adhes. Adhes. 50, 119-127.

Mihut, C., Captain, D.K., Gadala-Maria, F., Amiridis, M.D., 2001. Review: Recycling 
of nylon from carpet waste. Polym. Eng. Sci. 41(9), 1457-1470.

Nagarajan, V., Mohanty, A., Misra, M., 2013. Sustainable green composites: value addition to agricultural residues and perennial grasses. ACS Sustain. Chem. Eng. 1(3): 325-333.

Najib, N.N., Ariff, Z.M., Bakar, A.A., Sipaut,, C.S., 2011. Correlation between the acoustic and dynamic mechanical properties of natural rubber foam: Effect of foaming temperature. Mater. Design. 32(2), 505-511.

Ouis, D., 2001. Annoyance from road traffic noise: a review. J. Environ. Psychol. 21(1), 101-120.

Ozen, E., Kiziltas, A., Kiziltas, E.E., Gardner, D.J., 2013. Natural fiber blend-nylon 6 composites. Polym. Compos. 34(4), 544-553.

Qiu, Y.P., Batchelor, S.D., Jack, P.R., McCord, M.G., 2000. Estimation of the axial tensile modulus of a particle-reinforced composite fiber with variable radius. Compos. Sci. Technol. 60(14), 2731-2737.

Radhakrishnan, C.K., Sujith, A., Unnikrishnan, G., 2007. Thermal behaviour of styrene butadiene rubber/poly (ethylene-co-vinyl acetate) blends. J. Therm. Anal. Calorim. 90(1), 191-199.

Santos, P.A., Spinacé, M.A., Fermoselli, K.K., Paoli, M.A., 2007. Polyamide 6/vegetal fiber composite prepared by extrusion and injection molding. Compos. Part A-Appl. S 38(12), 2404-2411.

Schopp, S., 2014. Functionalized graphene and carbon materials as components of styrene - butadiene rubber nanocomposites prepared by aqueous dispersion 
blending. Macromol. Mater. Eng. 299 (3), 319-329.

Siller, H., Drescher, M., Saueressig, G., Lange, R., 2010. Fly-over source localisation on a boeing 747-400. 3rd Berlin Beamforming Conference, BoBec-2010, February 2010.

Subramanian, P.M., 2000. Plastics recycling and waste management in the US. Resour. Conserv. Recycl. 28(3), 253-263.

Wang, Y.J., Wu, H.C., Li, V.C., 2000. Concrete reinforcement with recycled fibers. J. Mater. Civil Eng. 12(4), 314-319.

Wang, Y., Zhao, D.M., 2006. Effect of fabric structures on the mechanical properties of 3-D textile composites. J. Ind. Text. 35(3), 239-256.

Wang, Y.J., 2010. Fiber and textile waste utilization. Waste Biomass Valor. 1(1), 135-143.

Zhang, H., Wang, Y., Wu, Y., Zhang, L., Yang, J., 2005. Study on flammability of montmorillonite/styreneebutadiene rubber (SBR) nanocomposites. J. Appl. Polym. Sci. 97(3), 844-849.

Zhao, J., Wang, X.M., Chang, J.M., Yao, Y., Cui, Q., 2010. Sound insulation property of wood-waste tire rubber composite. Compos. Sci. Technol. 70(14), 2033-2038.

Zhao, Y., Zhao, Y.Z., Xu, H.L., Yang, Y.,Q., 2015a. A Sustainable Slashing Industry Using Biodegradable Sizes from Modified Soy Protein To Replace Petro-Based Poly (Vinyl Alcohol). Environ. Sci. Technol. 49 (4), 2391-2397.

Zhao, Y.Z., Zhao, Y., Yang, Y.Q., 2015b. Modified soy protein to substitute non-degradable petrochemicals for slashing industry. Ind. Crop. Prod. 67 466-474. 
Zou, Y., Shah, H., Yang, Y.Q., 2010. Lightweight composites from long wheat straw and polypropylene web. Bioresour. Technol. 101(6), 2026-2033. 


\section{Figure Captions}

Fig. 1. Effect of concentration of nylon 6,6 carpets on the mechanical properties of the compression molded composites from nylon 6/nylon 6,6 carpets. Compression molded composites from nylon 6 carpets, nylon 6,6 carpets, nylon 6/nylon 6,6 (67/33) carpets and nylon 6/nylon 6,6 (33/67) carpets were made at $220{ }^{\circ} \mathrm{C}, 260{ }^{\circ} \mathrm{C}$ and $240{ }^{\circ} \mathrm{C}$ for $5 \mathrm{~min}$, respectively. Data points with different numbers, letters, or symbols indicate statistically significant difference.

Fig. 2. Effect of hot pressing temperature and holding time on mechanical properties of the compression molded composites from nylon 6/nylon 6,6 (33/67) carpets. Data points with different numbers, letters, or symbols indicate statistically significant difference.

Fig. 3. SEM images of the cross sections of the composites from nylon $6 /$ nylon 6,6 (33/67) carpets compression molded at different temperatures for different times: a) $220{ }^{\circ} \mathrm{C}$ and $3 \mathrm{~min}$, b) $220^{\circ} \mathrm{C}$ and $5 \mathrm{~min}$, c) $230^{\circ} \mathrm{C}$ and $3 \mathrm{~min}$, d) $230{ }^{\circ} \mathrm{C}$ and $5 \mathrm{~min}$, e) $240{ }^{\circ} \mathrm{C}$ and $\left.3 \min \mathrm{f}\right) 240{ }^{\circ} \mathrm{C}$ and $5 \mathrm{~min}$, g) $250{ }^{\circ} \mathrm{C}$ and $\left.3 \mathrm{~min} \mathrm{~h}\right) 250{ }^{\circ} \mathrm{C}$ and $5 \mathrm{~min}$. Magnification of SEM images (a-d) is $150 \times$.

Fig. 4. Effect of SRB and $\mathrm{CaCO}_{3}$ on the mechanical properties of the compression molded composites from nylon 6/nylon 6,6 carpets. Nylon 6/nylon 6,6 (33/67) carpet yarns with or without SBR, nylon 6/nylon 6,6 (33/67) carpets with or without $\mathrm{CaCO}_{3}$ were compression molded at $230{ }^{\circ} \mathrm{C}$ for 5 min. Data points with different numbers, letters, or symbols indicate statistically significant difference.

Fig. 5. Temperature dependence of storage modulus $\left(E^{\prime}\right)$ and loss factor $(\tan \delta)$ of 
compression molded composites from nylon 6 carpets, nylon 6,6 carpets and nylon 6/nylon 6,6 carpets.

Fig. 6. Water absorption and thickness increment of the compression molded composites from nylon 6/nylon 6,6 carpets and jute/PP (40/60) immersed in $20{ }^{\circ} \mathrm{C}$ water for 1 - 9 days a) increment of thickness, b) water absorption; In $50{ }^{\circ} \mathrm{C}$ water for 1 - 9 days c) increment of thickness, d) water absorption. Compression molded composites from nylon 6 carpets, nylon 6,6 carpets, nylon 6/nylon 6,6 (67/33) carpets and nylon 6/nylon 6,6 (33/67) carpets were made at $220^{\circ} \mathrm{C}, 260{ }^{\circ} \mathrm{C}$ and $230{ }^{\circ} \mathrm{C}$ for 5 min, respectively. Jute/PP composites were compression molded at $180{ }^{\circ} \mathrm{C}$ for $10 \mathrm{~min}$. Data points with same numbers or letters indicate no statistically significant difference.

Fig. 7. Sound absorption of the compression molded composites from nylon 6/nylon 6,6 carpets and jute/PP (40/60). Compression molded composites from nylon 6/nylon $6,6(33 / 67)$ carpet yarns with or without SBR, and nylon 6/nylon 6,6 (33/67) carpets were made at $220{ }^{\circ} \mathrm{C}, 260{ }^{\circ} \mathrm{C}$ and $230{ }^{\circ} \mathrm{C}$ for $5 \mathrm{~min}$, respectively. Jute/PP composites were compression molded at $180^{\circ} \mathrm{C}$ for $10 \mathrm{~min}$. 
Table 1 Comparisons of the mechanical properties of the compression molded composites from nylon 6/nylon 6,6 carpets, polypropylene carpets, and jute/polypropylene

\begin{tabular}{|c|c|c|c|c|}
\hline \multicolumn{2}{|c|}{$\begin{array}{c}\text { Mechanical } \\
\text { properties }\end{array}$} & $\begin{array}{c}\text { Nylon } \\
6 / \text { nylon } 6,6 \\
\text { carpets }^{\mathrm{a}}\end{array}$ & $\begin{array}{c}\text { Polypropylene } \\
\text { carpets }^{\mathrm{b}}\end{array}$ & $\begin{array}{c}\text { Jute/polypropylene } \\
(40 / 60)^{\mathrm{c}}\end{array}$ \\
\hline $\begin{array}{c}\text { Tensile } \\
\text { properties, } \\
\mathrm{MPa}\end{array}$ & Strength & $11.1 \pm 0.6$ & $9.9 \pm 0.5$ & $24.6 \pm 1.8$ \\
\cline { 2 - 5 } & Modulus & $1404.9 \pm 209.0$ & $1803.2 \pm 151.0$ & $1702.2 \pm 445.0$ \\
\hline $\begin{array}{c}\text { Flexural } \\
\text { properties, } \\
\mathrm{MPa}\end{array}$ & Strength & $31.7 \pm 0.7$ & $11.8 \pm 1.3$ & $20.0 \pm 1.3$ \\
\cline { 2 - 5 } & Modulus & $5707.5 \pm 331.0$ & $1397.1 \pm 796.0$ & $2549.9 \pm 205$ \\
\hline $\begin{array}{c}\text { Impact resistance, } \\
\mathrm{J} / \mathrm{m}\end{array}$ & $260.9 \pm 12.9$ & $176.0 \pm 10.5$ & $197.6 \pm 17.9$ \\
\hline
\end{tabular}

a were nylon 6,6/ nylon $6(66 / 34)$ carpets compression molded at $230^{\circ} \mathrm{C}$ for $5 \mathrm{~min}$. $\mathrm{b}$ and $\mathrm{c}$ were compression molded at $180{ }^{\circ} \mathrm{C}$ for $10 \mathrm{~min}$.

Density of a, b c was $1.3 \mathrm{~g} / \mathrm{cm}^{3}$; thickness of a is $4.5 \mathrm{~mm}$, thickness of $\mathrm{b}$ is $1.2 \mathrm{~mm}$, thickness of $\mathrm{c}$ is $4.0 \mathrm{~mm}$ 